\title{
The Case of the Port of Linaria-Skyros, Greece: The Human Factor as the Main Dimension of Impression and Other Findings in the GUESTBOOK Tourists' Evaluation
}

\author{
Aglaia Margariti \\ University of the Aegean, Mytilene, Greece \\ Kyriakos Antonopoulos \\ Skyros Port Fund, Skyros, Greece
}

\author{
Kalliopi Marini \\ University of the Aegean, Mytilene, Greece \\ Constantina Skanavis \\ University of the Aegean, Mytilene, Greece
}

\begin{abstract}
Tourism is an important factor for the economic development of a country. For the sustainable development of tourism, there is a code composed of ten principles, which aim to maximize the benefits and minimize the negative influence to already existing cultural heritage and environment. These ethics have to be followed by hosts and the tourists, for their satisfaction, respectively. The case of maritime tourism in Greece, because of its geographical location, its coasts and islands, plays a critical role in the country's economic growth. In this way marinas, which are usually called the big leisure ports, are considered to be very significant facilities (Diakomihalis, 2007). The present research aims to assess and analyze the visitors' feedback in the touristic port of Linaria-Skyros and also how the environment acts as a pull factor. The choice of Linaria port was made because of its great touristic interest, its innovative features as well as the environmental protection and training activities in house. Other surveys in the past like "Naxos Guest Satisfaction Survey" (Hotel Association of Naxos, August to October 2012) have been conducted with the use of questionnaires and personal interviews putting emphasis however mainly upon the guests' satisfaction. For this assessment, the guestbook of Linarias' port was used, and we came up with conclusions regarding the quality of the port as well as tourists' psychological identity. The guestbook used here, contains comments from 2012 to 2014, based on free expression of individuals' need to share their Skyros port experience. In the first place, all comments and keywords of the guestbook were treated as a total for all the years covered. Secondly, they were separated based on the year they were written, their quality and their content, so as to allow the comparison of the results. Tourists have shown more interest in human factors than the provided services of the port. Also, some tourists claimed extension of their stay from 2 to 10 days. According to the findings, the environmental actions taking place in the port's facilities (tourism observatory, environmental camp, environmental trails) appeared to be the main reasons of tourists' positive impressions, satisfaction, their willing to extend their stay and to visit the island again in the future.
\end{abstract}

Keywords: Linarias' port guestbook, maritime tourism, visitor's impression, tourists satisfaction, comments and feelings, human factor, staffs' behavior and service, hospitality

Kyriakos Antonopoulos, Skyros Port Fund, Linaria Port.

Aglaia Margariti, Department of Environment, University of the Aegean.

Kalliopi Marini, Ph.D. Candidate, Department of Environment, University of the Aegean.

Constantina Skanavis, Professor, Department of Environment, University of the Aegean. 


\section{Introduction}

Maritime tourism is one of the world's largest industries of contemporary tourism, with a significant participation in the tourist economies of the countries which have developed it (Hall, 2001), and with a tendency for continuous and fast rates of development (Orams, 1999). "The extraordinary beauty, cultural wealth and great diversity of EU's coastal areas have made them the preferred destination for many people in Europe and abroad, making coastal and maritime tourism an important tourism sector" (European Commission, 2016). At an international level, it includes the total of tourists and activities which take place in the marine space of the country offering hospitality to tourists. The development of Maritime tourism in Greece began during the 1960s'. One of the main inputs of Greek tourism investments is the ports. "The establishment and operation of port and land services for leisure crafts constitute an essential infrastructure for the development of maritime tourism" (Diakomihalis, 2007). An assessment way, in this case, of a touristic port, is through visitors' satisfaction.

However, the development of maritime tourism has serious consequences on the environment. Seas and coasts are among the most complex, vulnerable and sensitive to all natural ecosystems, making their management difficult (Beriatos \& Papageorgiou, 2011). The need of environmental protection led to the adoption of international agreements, guidelines and national law regulations. In this way, ports have to adopt a protective case for the environment, where the concept of sustainable development is being emphasized (Sakellaropoulou, 2016).

An exceptional example is the small Port of Linaria-Skyros, which has adopted a new way of sustainable approach to manage environmental impacts.

This Greek small public port, with few resources has succeeded to attract tremendous publicity and has been recorded as the fuller and friendliest public port of Greece (Antonopoulos, Skanavis, \& Plaka, 2015). In this context, based on free expression of tourists, this research aims to contribute to the fact that tourists' embodiment in relation to environments visited is hardly addressed or evaluated. In this sense, the intention of this study is to classify, assess and analyze the visitors' feedback, using the guestbook, in the touristic port of Linaria-Skyros and also how the environment acts as a pull factor.

\section{Research Methodology}

For the needs of this research, the first volume of the Guest Book of Linarias' Port was used. This means that the comments begin as soon as guests start using it and this was in July 2012 up to September 2014. The total sample consisted of 421 comments of visitors. All 421 comments were classified based on their language. After that, the comments were classified by the year and by the months for each year they were written. This helped to draw conclusions about how frequently the book was used and how eager the visitors were to comment each year.

From the comments in total, the 350 had a recognizable way of writing, so the biggest part of this research is based on them. Initially, in these 350 comments, the words most frequently used were isolated and counted. This helped to answer the question, to a certain extent, "what attracts most visitors' attention" whether they come for the first time or not. In addition, keywords were counted for each year separately to allow comparison. The duration of the stay was mentioned in some comments as well as the way visitors felt about it so we were able to draw conclusions and understand their feelings. Most comments were extremely positive, but there have also been noted deficiencies concerning some of marinas' facilities.

All these different comments and comparisons are presented in an analytical way below along with each result. 


\section{Results}

The sample of this research is 421 comments of Linarias' port guestbook.

More than half of the guestbooks' comments were written in English language with percentage $50.71 \%$, while in Greek language is just $24.53 \%$. French and German comments were also present with percentages 6 , $83 \%$ and $4.01 \%$ respectively. Last but not least, other languages such as Italian Spanish and Russian possess $13.91 \%$ (Figure 1).

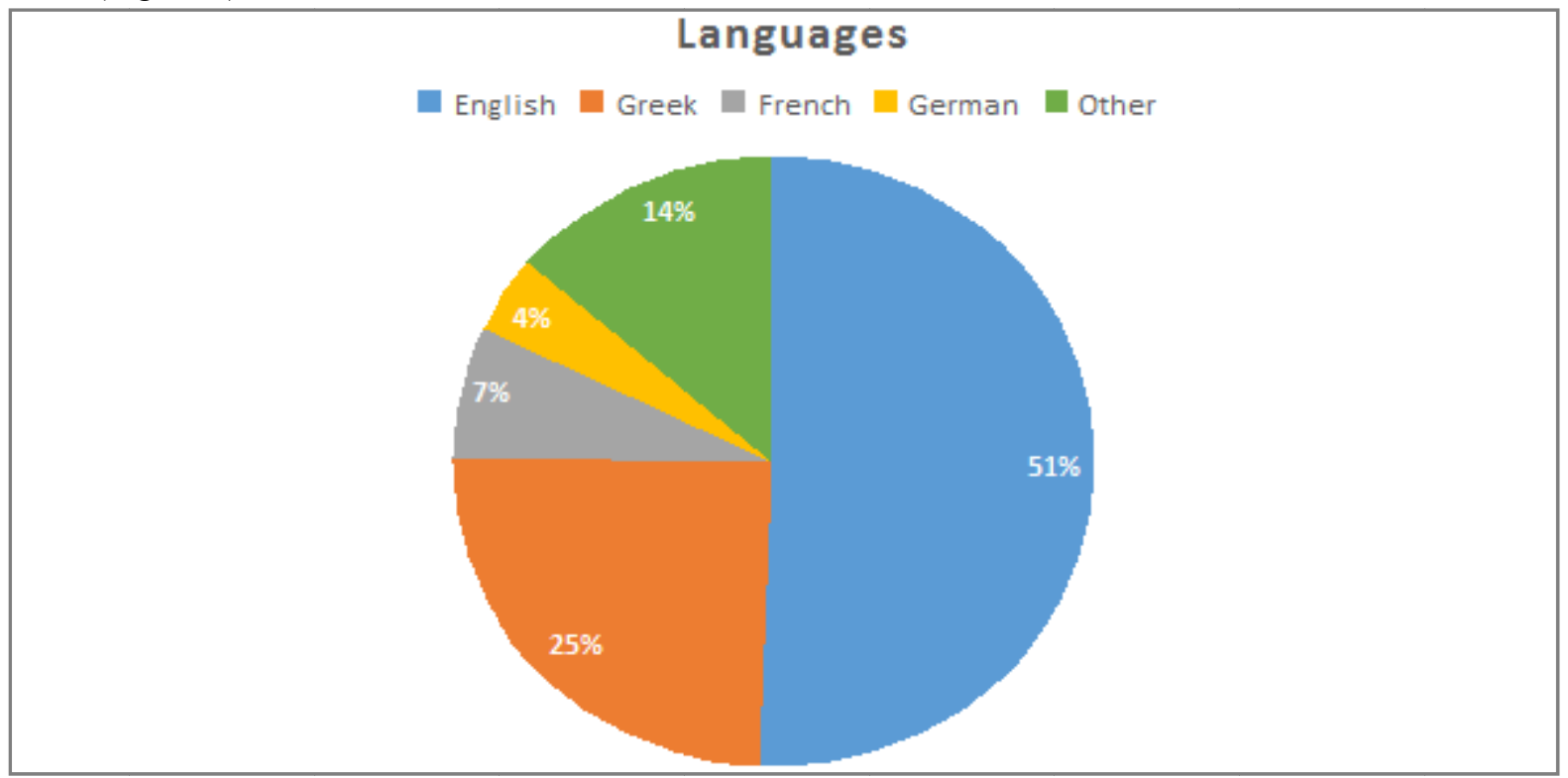

Figure 1. Comments being classified by language they were written.

All 421 comments were classified according to year, and as it seems in the Figure 2, the highest percentage $43.20 \%$ belongs to 2013 , while 2012 and 2014 follow occupying $28.63 \%$ and $28.16 \%$ respectively.

\section{Comments per year}

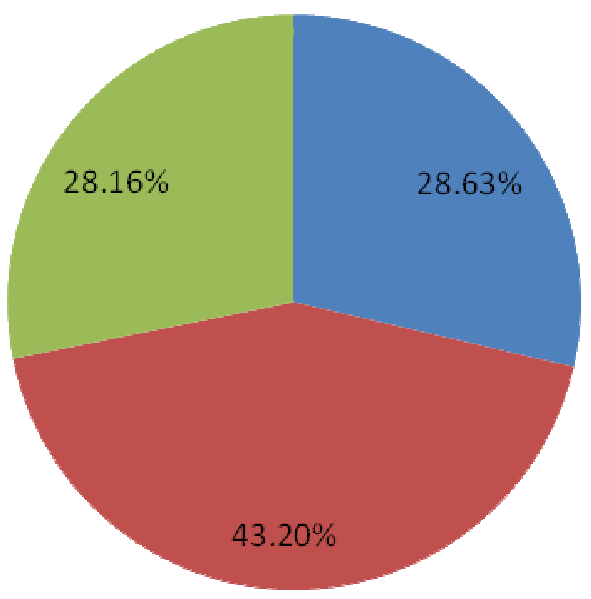


From the 350 readable comments, the keywords according to the benefits of the port reported by the majority of visitors appear in Figure 3.

More specifically words as staff, service, welcoming and hospitality were mostly used in comments, percentages of which range between $27.43 \%-23.43 \%$. Next on, $22.96 \%$ talked about help, while words as organization and cleanliness account $21.43 \%$ and $21.14 \%$ respectively. A percentage of $20.86 \%$ correspond to "people", while about $18.86 \%$ were talking about revisit. About $16.86 \%$ reported the equipment, but also facilities and information were mentioned with percentages $14.29 \%$ and $11.14 \%$ respectively. $7.7 \%$ referred to food. Keywords occupying least percentages were security (3.71\%) and prices (3.71\%). Last but not least only the $4 \%$ said that they would recommend the island as a destination.

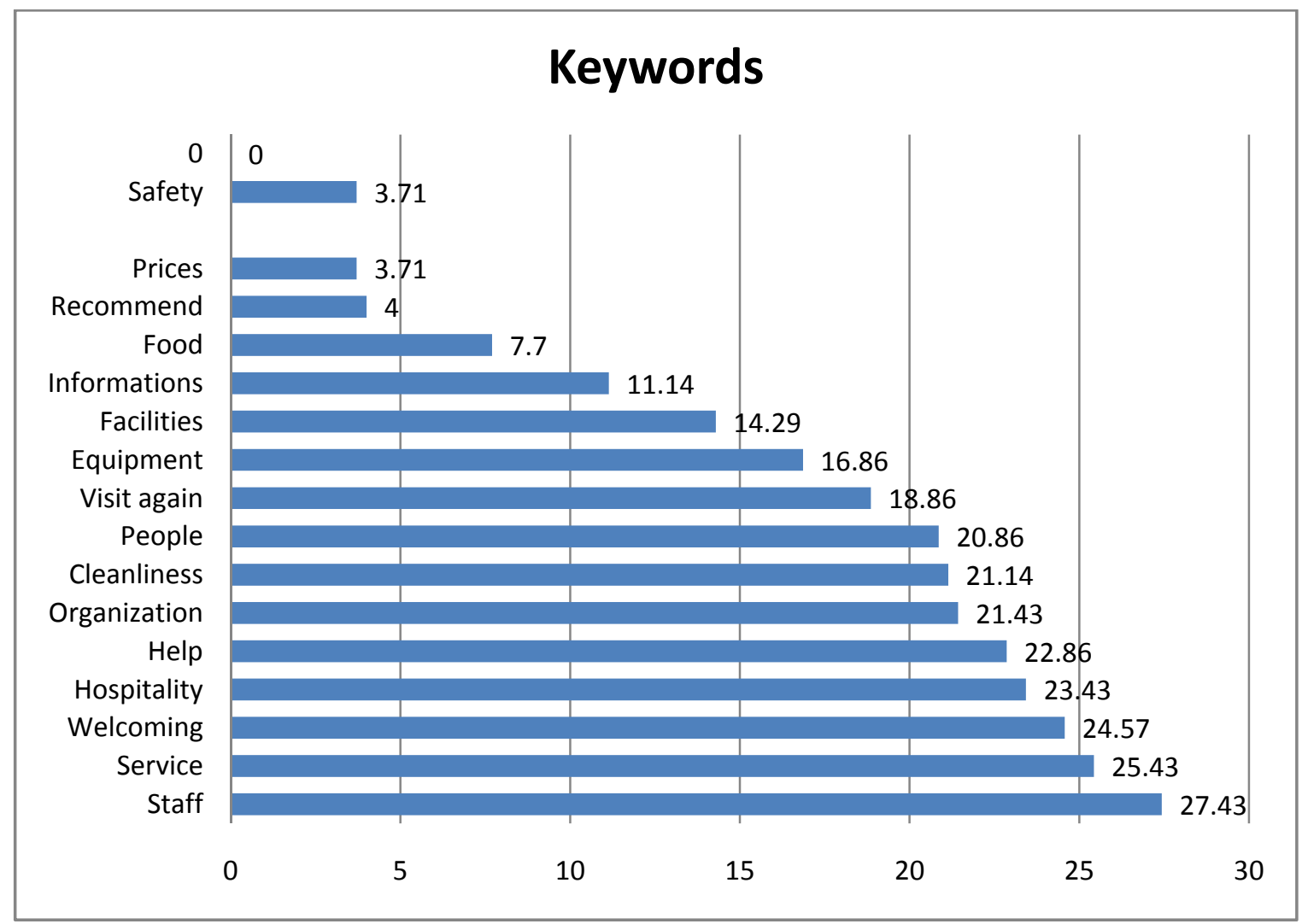

Figure 3. Keywords' percentages of guestbook in total.

Figure 4 appears that the year 2012 contains comments from 4 months, 2013 has 8 months' comments and the comments of 2014 are from 9 months.

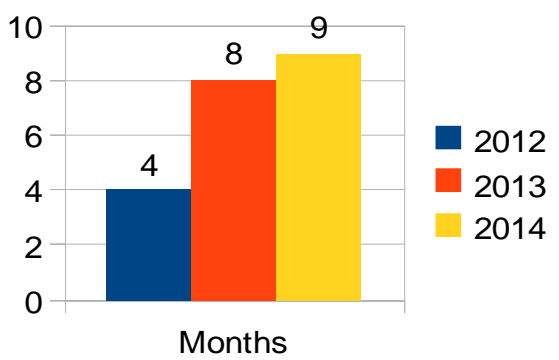

Figure 4. Months that every comment was written in each year. 
As visible in Figure 5, during the year 2012, most frequently used keywords in comments were: staff, cleanliness and service - which in the next two years were even less used. However, the word "staff" remained the most frequent reference in both 2012 and 2013, while in 2014, highest percentage has the word "help" and the information was given from the staff, whilst quite similar is the percentage of comments using this word over the years 2012-2013 (about 22\% and 10\% respectively). Only in 2013 tourists commented about safety.

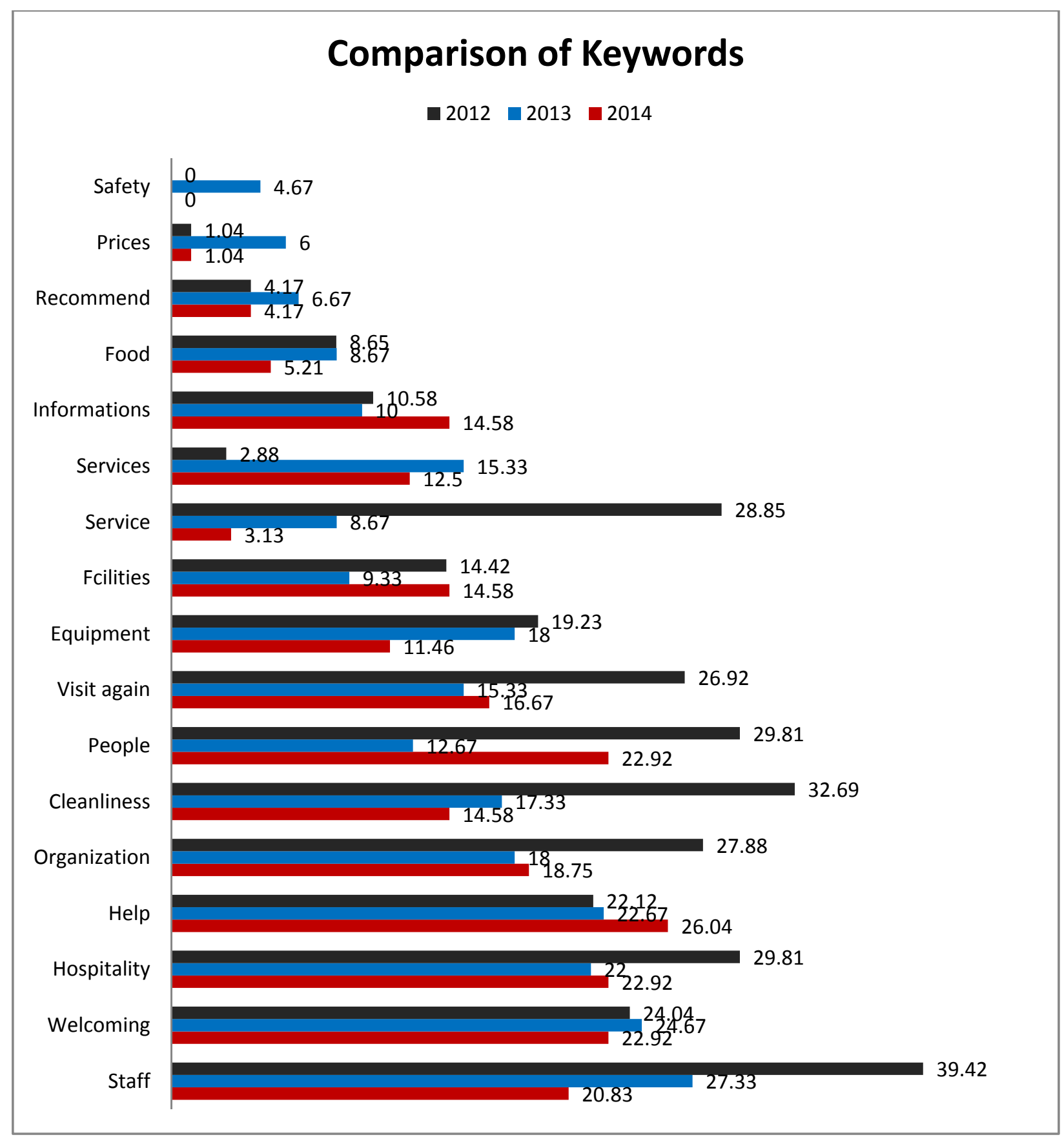

Figure 5. Keywords being compared to the years 2012, 2013 and 2014.

As can be seen in Figure 6, the $25 \%$ of visitors' comments relating to the duration of residence, reported that they stayed more than 7 days and many of them emphasized the extension of their stay from 2 up to 10 days. 


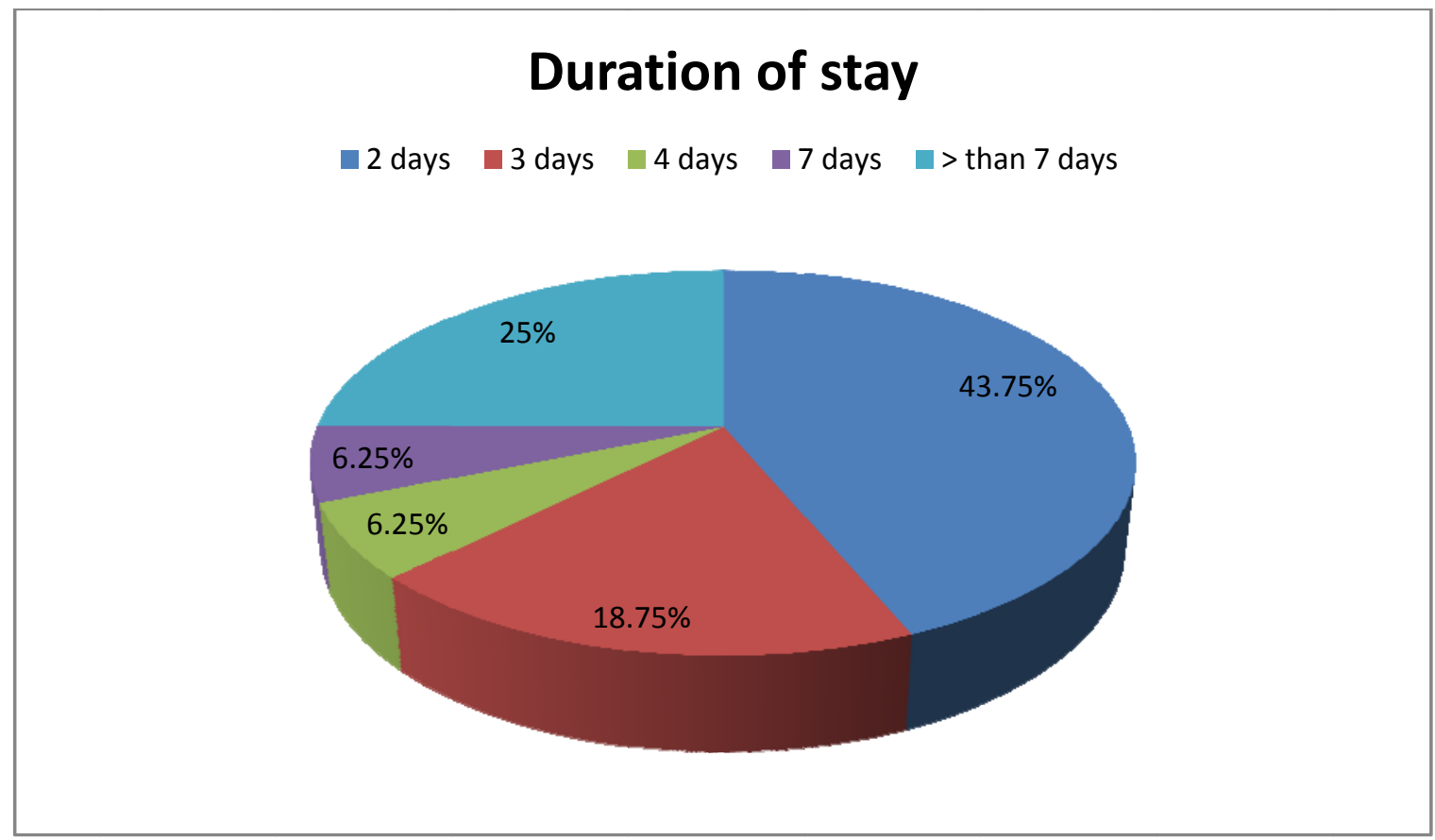

Figure 6. Percentages of the duration of visitors' stay.

Figure 7 is presenting the visitors' satisfaction about their stay. More specifically, they described their stay as pleasant $(44.83 \%)$ and charming $(10.34 \%)$. Also comfortable $(6.9 \%)$, enjoyable $(6.9 \%)$ and wonderful $(6.9 \%)$.

*others (2\%): relaxing, calm, beautiful, fantastic.

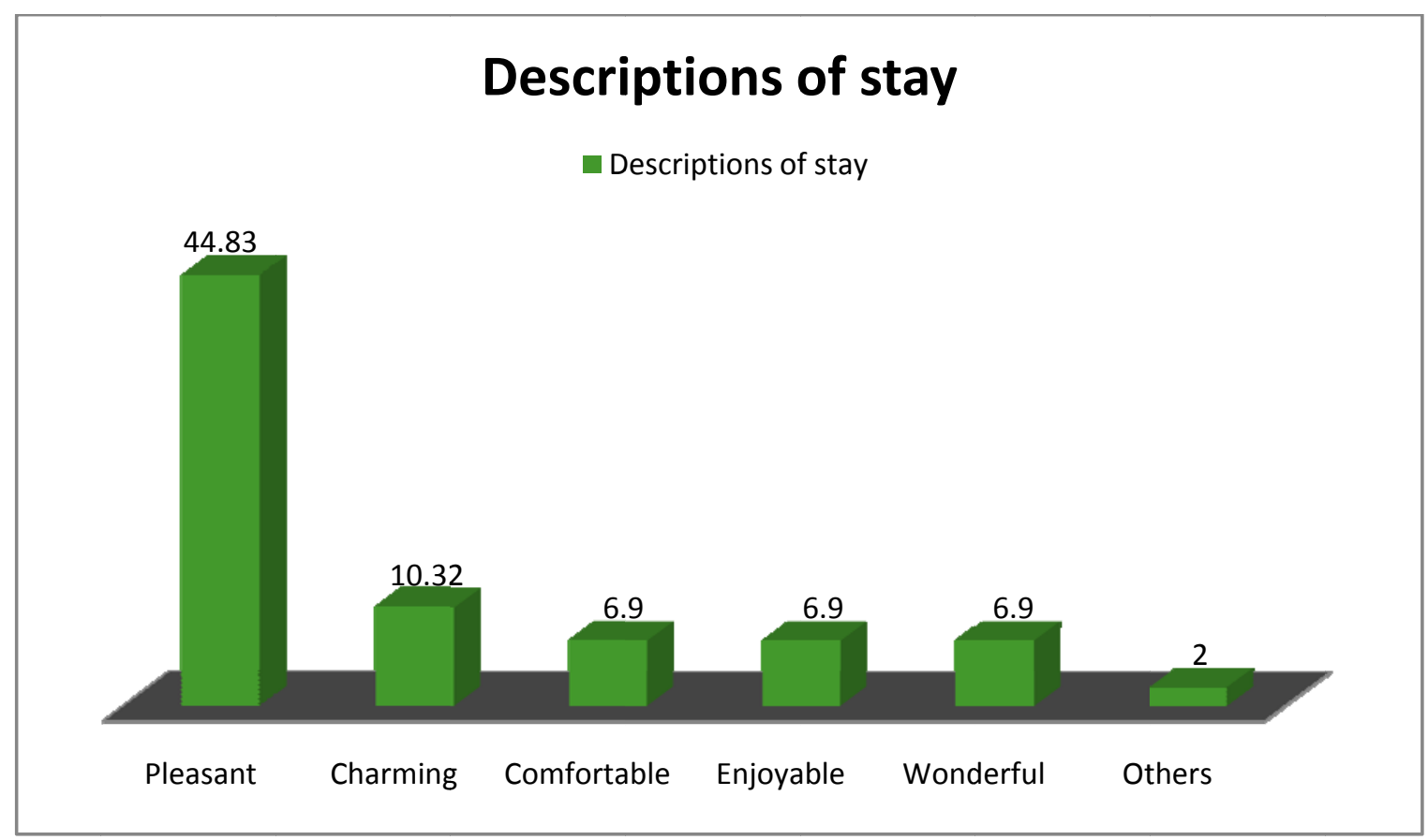

Figure 7. Percentages of how the visitors described their stay. 
The majority of the comments were positive, as presented in Figure 8. Nevertheless, the 3.71\% complained mostly about some lack of facilities (atm and bunkering station).

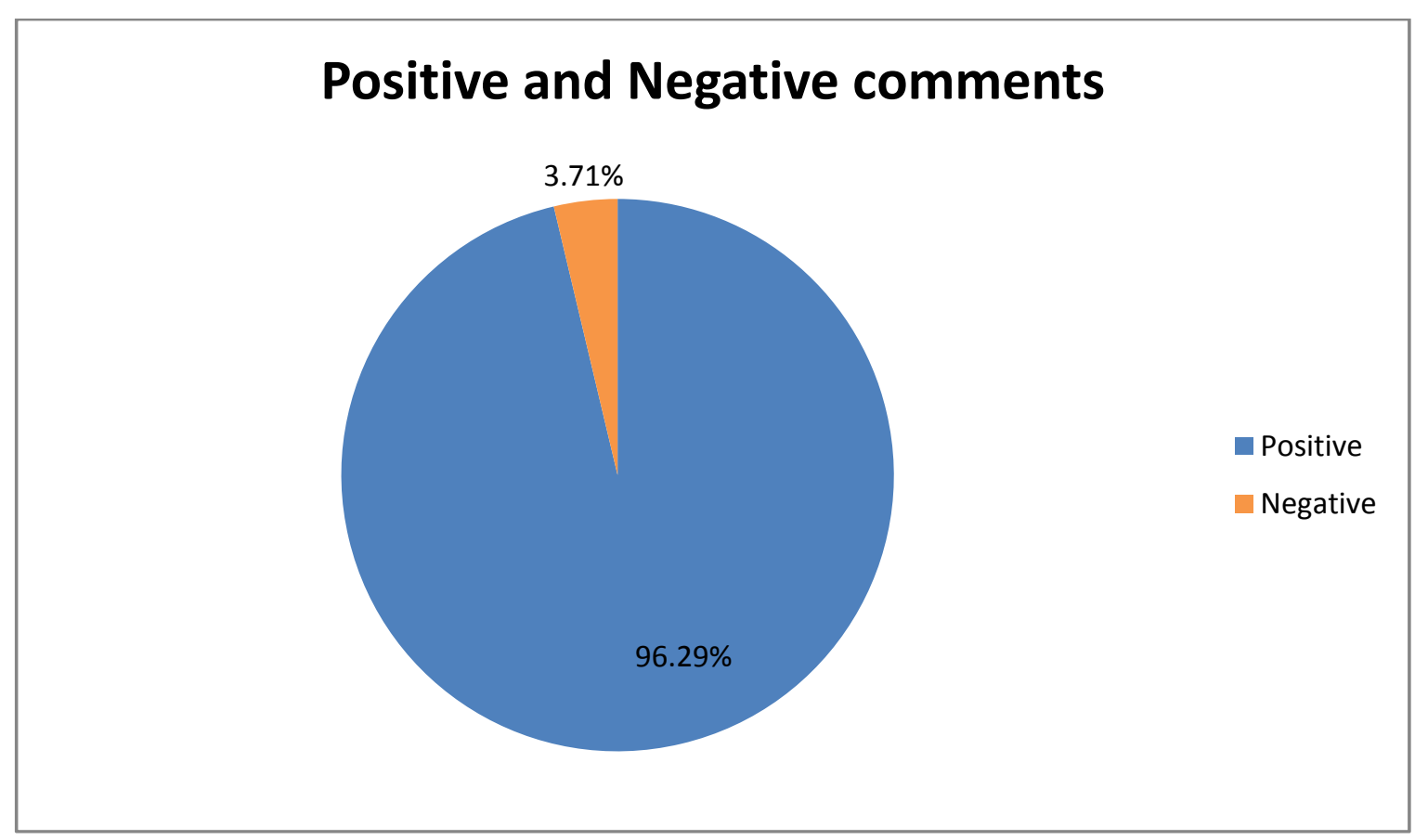

Figure 8. Positive comments and complains.

\section{Conclusions}

The guest book is a way for visitors to freely express themselves and in this way the place is indirectly criticized. Anyone can write whatever impressed or disappointed him/her, thus taking into account each one's comments, can make substantial progress. This research which was based on the results by analyzing and grouping the comments of Linaria's guest book found some conclusions. Conclusions mainly concern the quality of residence of tourists compared with the port and staff in connection with the environment and the atmosphere of the island.

In the first place, the majority of the sample, i.e 3/4, was written in foreign languages, English being most frequently used. Comments in Greek language accounted only $25 \%$. According to that, here is the question: foreigners were more willing to write in the book? Or visitors from other countries were more than Greeks? Amount of each year's Comments depends on the book use. This conclusion comes from number of comments during 2012 and 2013 posted during a period of 4-8 months respectively. Amount of comments during 2014 is similar to 2012. However, they were posted during a period of 9 months. As we were informed, this is due to less frequent handling of the book from staff to visitors.

According to the results of this assessment, it seemed that tourists, apart from the environment and place, paid particular attention to the human factor. The warm welcome, the immediate response to help and friendly attitude of staff were major factors that led to a satisfactory stay. Here the equipment assumes the port facilities that are standard for a marina.

The vast majority of the samples were positive comments, occupying $98 \%$, which indicates the satisfaction of tourists. This satisfaction depends on many factors such as the expectations, which have a positive and 
significant influence (Rodriguez del Bosque \& San Martin, 2008), preferences of individuals and the environment. Image plays an important role too and it is defined as an individual's mental representation of knowledge, feelings, and global impressions about a destination (Baloglu \& McCleary, 1999).

According to the results, the average of stay was three days. Reported however and extension up to 10 days, primarily because of the atmosphere and the environment of Skyros. According to Loken (2006), the importance of emotions in behavior models has increased significantly during the last few years and also plays an important role in tourism since individuals' enjoyment is based on their own experiences. Positive emotions are the main determinant in satisfaction formation (Rodriguez del Bosque \& San Martin, 2008). More specifically under the designations used in comments to stay, it concludes that prevail positive emotions like pleasure, tranquility and joy. Negative emotions play a significant role in satisfaction formation too (Rodriguez del Bosque \& San Martin, 2008).

The minimum negative comments specifically referred to some lack of facilities, no atm and bunkering station at the port. In 2014 progress has been made as there are no negative comments. As during 2013 atm was established at the port and later in the summer of 2016, the first bunkering mixed station in Greece was opened.

From the analysis of the data it appears that the visitors have shown interest more about human factors than on the equipment and the facilities of the port.

More specifically for the year 2012, the visitors referred more to the staff, hospitality, the friendliness of the people and the services provided by the staff.

The measurement of service quality through visitor satisfaction survey may be considered as the most reliable information for the performance evaluation of any organization. Thereby, it is possible to analyze the behavior and determine future improvement actions and programs based on the voice of the visitor (Arabatzis \& Grigoroudis, 2009).

Satisfaction and service quality are some of the variables which are used to evaluate the travel destination (Weaver, Weber, \& McCleary, 2007). The positive influence of service quality on purchase intentions is greater when satisfaction is also greater (Taylor \& Baker, 1994).

In 2014 tourists comment for the help and information were provided, more than the other years, and that's because with the passage of time there was specialization.

Image plays an important role too and it is defined as an individual's mental representation of knowledge, feelings, and global impressions about a destination (Baloglu \& McCleary, 1999).

Finally, tourists' satisfaction is a factor that affects positively the intention to revisit a destination in the future and the willingness to recommend it to other people (Yoon \& Uysal, 2005).

\section{Limitations and Further Research}

The first limitation of this study is the most frequent use of the guest book, so there would be more specific results about the willingness of visitors to write down their experiences. Because this research is based on visitors' free expression, it would be useful for a further research the use of questionnaires. Some of the questions could be about demographics and the expectations of visitors for the port and also for the island.

\section{References}

Antonopoulos, K., Scanavis, C., and Plaka, V. (2015). Exploiting further potential of linaria Port-Skyros: From vision to realization.

Arabatzis, G., and Grigoroudis, E. (2010). Visitors' satisfaction, perceptions and gap analysis: The case of 
Dadia-Lefkimi-Souflion National Park. Forest Policy and Economics, 12, 163-172.

Beriatos, E., and Papageorgiou, M. (2011). Maritime and coastal spatial planning: The case of Greece and the Mediterranean. Sustainable Development and Planning V, 150, 3-17.

Baloglu, S., and McCleary, K. (1999). A model of destination image formation. Annals of Tourism Research, 26, 868-897.

Diakomihalis, M. (2007). Chapter 13 Greek maritime tourism: Evolution, structures and prospects. Research in Transportation Economics, 21, 419-455.

Hall, M. (2001). Trends in ocean and coastal tourism: The end of the last frontier? Ocean \& Coastal Management, 44(9-10), 601-618.

Loken, B. (2006). Consumer psychology: Categorization, inferences, affect, and persuasion. Annual Review of Psychology, 57, 453-485.

Miller, M. (1993). The rise of coastal and marine tourism. Ocean \& Coastal Management, 20(3), 181-199.

Orams, M. (1999). Maritime tourism: Development, impacts and management.

Rodriguez del Bosque, I., \& San Martin, H. (2008). Tourist satisfaction: A cognitive-affective model. Annals of Tourism Research, 35(2), 551-573.

Sakellaropoulou, K. (2016). Nomos+Physis, economic crisis and the protection of the natural environment. Accessed November 18, 2016. http://nomosphysis.org.gr/15119/oikonomiki-krisi-kai-prostasia-toy-fysikoy-perivallontos/[18 November 2016].

Taylor, S., \& Baker, T. (1994). An assessment of the relationship between service quality and customer satisfaction in the formation of consumers' purchase intentions. Journal of Retailing, 70(2), 163-178.

Weaver, P., Weber, K., \& McCleary, K. (2007). Destination evaluation: The role of previous travel experience and trip characteristics. Journal of Travel Research, 45(3).

Yoon, Y., \& Uysal, M. (2005). An examination of the effects of motivation and satisfaction on destination loyalty: A structural model. Tourism Management, 26, 45-56. 